\title{
An Update on Sjögren’s Syndrome for Oral Medicine Specialists
}

Won Jung, Kyung-Eun Lee

Department of Oral Medicine, Institute of Oral Bioscience, School of Dentistry, Jeonbuk National University, Jeonju, Korea

\author{
Received December 6, 2021 \\ Revised December 9, 2021 \\ Accepted December 9, 2021 \\ Correspondence to: \\ Kyung-Eun Lee \\ Department of Oral Medicine, School of \\ Dentistry, Jeonbuk National University, 567 \\ Baekje-daero, Deokjin-Gu, Jeonju 54896, \\ Korea \\ Tel: +82-63-250-2060 \\ Fax: +82-63-250-2058 \\ E-mail: lke@jbnu.ac.kr \\ https://orcid.org/0000-0001-8923-1478
}

Sjögren's syndrome $(\mathrm{SjS})$ is a common autoimmune disorder characterized by lymphocytic infiltration in the salivary and lacrimal glands, resulting in severe dry mouth or eyes. The symptoms are complex and heterogeneous. Several diagnostic criteria have been proposed for SjS and its subsets over the years. However, on the other hands, great efforts have been made searching for reliable biomarkers able to ameliorate the diagnostic algorithm and the prognostic stratification of SjS patients. The aim of this article is to review biomarkers and treatments related to $\mathrm{SjS}$ for oral medicine specialists.

Key Words: Biomarkers; Oral medicine; Sjögren's syndrome; Therapeutics

\section{INTRODUCTION}

Sjögren's syndrome ( $\mathrm{SjS}$ ) is a systemic autoimmune disorder characterized by lymphocytic infiltration in the salivary and lacrimal glands, resulting in severe dry mouth or eyes [1]. More than half of SjS patients also have extra-glandular manifestations, such as mainly arthralgia, fatigue, and myalgia [2]. Variability of these symptoms may make the diagnosis of $\mathrm{SjS}$ be delayed up to 9 years after the onset of symptoms [3].

Several diagnostic criteria have been proposed for $\mathrm{SjS}$ and its subsets over the years [4-6]. The 2002 modified European-American diagnostic criteria considered two symptoms (ocular and oral dryness) and four signs (ocular signs, oral signs, histopathology, and autoantibodies) as key elements of diagnosis of SjS [4]. In 2012, criteria proposed by American College of Rheumatology (ACR) focused mainly on objective signs of positive focus score, serology, and ocular staining score [5]. The 2012 ACR was replaced by another system proposed by the International Sjögren's Syndrome Criteria Working Group, known as the 2016 ACR/EULAR (European League against Rheumatism)
Classification. This set give weighted points for the four objective signs [6]. Main components of these diagnostic criteria include histological examinations of minor salivary glands for lymphocytic infiltration and serology [4-6]. However, the biopsy is an invasive procedure that is not accepted by all patients, and it may delay definitive diagnosis [7]. Antibodies proposed on the above classifications are always not detected in all patients of SjS [6]. Biomarkers, which are noninvasive, specific to diagnose, sensitive to treatment, or useful to predict disease development of $\mathrm{SjS}$, are urgently needed for these reasons [7]. Great efforts have been made searching for reliable biomarkers able to ameliorate the diagnostic algorithm and the prognostic stratification of SjS patients and ultimately allowing the scientific community to address some of the unmet needs for the disease [8].

Oral dryness is one of the most common symptoms of patients who visit the department of oral medicine [9]. It is also the most common complaint of SjS patients [1]. Therefore, oral medicine specialists need to be alert to current knowledge as well as basic aspects mentioned in author's previous article [10]. The aim of this article is to 
review biomarkers and treatments related to $\mathrm{SjS}$ for oral medicine specialists continuing from a previous article [10]. In the first part, we have summarized the conventional and transitional biomarkers for SjS. In the second part, we have explored some of the novel potential biomarkers for the disease that have been proposed more recently. In the third part, we have summarized managements for oral and systemic manifestations.

\section{CONVENTAIONAL AND TRANSITIONAL BIOMARKERS FOR SJÖGREN'S SYNDROME}

\section{Anti-SSA/Ro and Anti-SSB/La Antibodies}

Clark et al. [11] identified two cytoplasmic proteins which were termed Ro and La from sera of systemic lupus erythematosus (SLE) patients in 1969 and 1974 [12]. Later, Alspaugh and Tan [13] reported the occurrence of antibodies to two cellular antigens, termed SS-A and SS-B, from sera of SjS patients. In 1979, Alspaugh and Maddison [14] showed agreement between Ro and SS-A, and La and SSB. Since then, it is known that the SSA/Ro antigens are nuclear and cytoplasmic polypeptides which serve as autoantigens in SLE and SjS. Anti-SSA/Ro and anti-SSB/La antibodies were found in approximately 50\% to 70\% of SjS patients. Anti-SSA/Ro antibodies were detected either solely or concomitantly with anti-SSB/La antibodies, whereas exclusive anti-SSB/La antibodies positivity was rare [15]. Finally, the ACR/EULAR decided to exclude anti-SSB/La antibodies from diagnostic criteria of $\mathrm{SjS}$ as an item based on group discussions and on a study demonstrating that the presence of anti-SSB/La antibodies without anti-SSA/Ro antibodies had no significant association with SjS phenotypic features, relative to seronegative participants [6].

\section{Rheumatoid Factor}

Rheumatoid factor (RF), a class of immunoglobulins (Ig) that has different isotypes and affinities, was first detected more than 70 years ago and has commonly been found in the sera of SjS patients [16]. RF is present in up to 70\% of SjS patients and its positivity has been associated with younger age, female predominance, positive salivary gland biopsy, and extra-glandular manifestations. Both the presence and the concentration of RF have been positively correlated to the number of extra-glandular manifestations found in SjS [15].

However, RF can be found in patients with other autoimmune such as such as SLE, mixed connective tissue disease, polymyositis, and dermatomyositis and also found in nonautoimmune conditions as well as in healthy subjects [17]. Thus, it may not be useful for clinical diagnosis or research classification purposes although RF is a prognostic finding in $\mathrm{SjS}$ patient [18].

\section{Anti-nuclear Antibodies}

Anti-nuclear antibodies (ANAs) are a class of antibodies that bind to cellular components in the nucleus including proteins, DNA, RNA, and nucleic acid-protein complexes [19]. Since they were first described in 1948, ANAs identification has been the foundation of diagnosis for connective tissue autoimmune disorders including SLE, SjS, and polymyositis/dermatomyositis. Increased titers are characteristic of individuals with connective tissue disorders, although $20 \%$ to $30 \%$ of the average population has detectable levels of ANAs [20].

ANAs, along with RF, are parameters commonly measured in $\mathrm{SjS}$ as clinical and diagnostic tools [21]. ANAs detected by indirect immunofluorescence on HEp-2 cells were found positive in 59\% to $85 \%$ of SjS patients. Positive patients for ANAs in SjS were more frequently female and had a lower mean age at diagnosis than males. ANAs were also characterized by a higher prevalence of recurrent parotidomegaly and an increased frequency of extra-glandular features, such as Raynaud phenomenon, cutaneous vasculitis, articular and renal involvement, fever, adenopathies, cytopenias and erythrocyte sedimentation rate $($ ESR) $>50$ $\mathrm{mm} / \mathrm{h}[15]$.

Huo et al. [22] showed that ANAs sand RF had the predictive and prognostic values for those who did not fulfill the higher stringent 2002 revised criteria but were indicated for immunomodulatory therapy. They suggested that ANAs and RF should be reconsidered as items of classification criteria for SjS. Theander et al. [23] found at least one autoantibody specificity (ANAs, RF, anti-SSA/Ro antibody, and anti-SSB/La antibody) in 81\% of 117 primary SjS patients up to 20 years before diagnosis, being the highest positive predictive values for anti-SSA/Ro antibodies. 


\section{Anti- $\alpha$-fodrin Antibodies}

The antigen recognized by the anti- $\alpha$-fodrin antibodies is a $120 \mathrm{kDa}$ cleavage product of $\alpha$-fodrin, which is formed during apoptosis in the inflamed salivary gland tissue and represents an organ-specific autoantigen that may be responsible for the development of autoimmune lesions and the perpetuation of tissue destruction. In 1997, Haneji et al. [24] found that the anti- $\alpha$-fodrin antibodies were specifically expressed in the lesional salivary glands and had a very high sensitivity (96\%) in the diagnosis of SjS. Anti- $\alpha$ fodrin IgG was detected in 22 studies whereas anti- $\alpha$-fodrin IgA was detected in 11 studies. The sensitivities of anti- $\alpha$ fodrin IgG for the diagnosis of $\mathrm{SjS}$ in the involved studies were from $6 \%$ to $100 \%$ and specificities were from 33\% to $100 \%$, respectively. For anti- $\alpha$-fodrin IgA, the sensitivities were from $17 \%$ to $62.6 \%$ and specificities were from $71 \%$ to $100 \%$. Hu et al. [25] concluded that anti- $\alpha$-fodrin antibodies as a marker showed moderate accuracy for the diagnosis of SjS. Willeke et al. [26] observed clinical and immunological characteristics in primary SjS patients with and without antibodies to $\alpha$-fodrin and showed a positive correlation of $\alpha$-fodrin antibody serum concentrations and the degree of lymphocytic infiltration in salivary glands. Qin et al. [27] suggeted anti- $\alpha$-fodrin IgG and IgA may be useful diagnostic markers which may improve the accuracy of SjS diagnosis.

\section{Anti-centromere Antibodies}

Anti-centromere antibodies (ACAs) are commonly found among patients with limited cutaneous scleroderma. The prevalence of ACAs in primary $\mathrm{SjS}$ ranges from $4 \%$ to $27.0 \%$ when detected by indirect immunofluorescence. ACAs Positive patients had a higher mean age at disease onset and a greater frequency of Raynaud's phenomenon, keratoconjunctivitis sicca, peripheral neuropathy and concomitant autoimmune disorders, such as primary biliary cirrhosis when compared to the ACAs negative group [15]. Lee et al. [28] also found that ACAs positive SjS patients had a higher prevalence of Raynaud's phenomenon, sclerodactyly and autoimmune thyroiditis and a lower prevalence of anti-SSA/Ro and anti-SSB/La antibodies compared to ACAs negative patients. These patients were associated with more severe objective ocular sicca and more severe subjective and objective oral sicca compared to healthy controls $[29,30]$. These results may show that patients with $\mathrm{SjS}$ who have ACAs differ from classic SjS patients in several clinical and laboratory parameters and should be monitored the occurrence of these clinical features in caution [28-30].

\section{Anti-salivary Protein 1, Anti-carbonic Anhydrase 6, and Anti-parotid Secretory Protein Antibodies}

Anti-salivary gland protein 1 (anti-SP1), anti-carbonic anhydrase 6 (anti-CA6), and anti-parotid secretory protein (anti-PSP) autoantibodies were first identified from interleukin 14 alpha transgenic mouse [31]. Since these antibodies were found from animal models of SjS, they have been found in patients with SjS both with anti-SSA/Ro and anti-SSB/La antibodies and without together, as well as in patients with idiopathic dry mouth and dry eye disease [32,33]. Martín-Nares and Hernández-Molina showed that anti-SP1, anti-CA6 and anti-PSP antibodies occurred in an earlier stage than anti-SSA/Ro and anti-SSB/La antibodies and might identify a subset of SjS patients with mild or incomplete disease [34]. One of the novel aspects of anti-SP1, CA6, and PSP is that they are found selectively in the salivary and lacrimal glands compared to anti-SSA/Ro and anti-SSB/La antibodies which are found virtually in every cell. It is unclear why anti-SSA/Ro and anti-SSB/La antibodies, found in SLE and various other autoimmune diseases, should be specific for SjS [35].

\section{NEW POTENTIAL BIOMARKES FOR SJÖGREN'S SYNDROME}

SjS patients despite apparently similar in their clinical presentation, may have a different long-term outcome and conventional biomarkers are generally not predictive of clinical outcome. The urgent need for biomarker development in SjS has been promoted [36].

\section{Anti-muscarinic Type 3 Receptor Antibody}

Muscarinic type 3 receptor (M3R) is one of the new promising biomarkers with direct biological and functional links to exocrine secretion. It is suspected that antibodies towards M3R may potentially inhibit saliva secretion and some have reported a $60 \%$ to $80 \%$ concordance of anti-M3R antibody 
with SjS [21]. Deng et al. [37] evaluated the diagnostic value of anti-M3R antibody in SjS by a meta-analysis and suggested that anti-M3R antibody had high specificity but relatively low sensitivity for the diagnosis of SjS. Zuo et al. [38] analyzed clinical parameters of primary $\mathrm{SjS}$ in association with anti-M3R antibody. It was significantly elevated in SjS plasma in comparison with healthy controls, SLE, or rheumatoid arthritis. SjS anti-M3R intensities were greater than two-standard deviations above the healthy controls. Furthermore, anti-M3R antibody was associated with antiSSA/Ro antibody positivity with focus score and had negative associations with saliva flow rate. However, anti-M3R antibody is not widely used as a biomarker in clinical settings, as the usage has been hampered by reproducibility issues [21]. Currently, Mona et al. [39] analyzed plasmaanti-M3R antibody in primary SjS using the modified oncell western assay with the stable cell line expressing human M3R-GFP protein and showed that it was higher in SjS compared to other control groups, differentiating SjS with good-to-excellent diagnostic power with a specificity of $85 \%$ and a sensitivity between $75 \%$ and $98 \%$. These results could underscore anti-M3R antibody in SjS diagnosis, where clinical assessments by multi-disciplinary specialists, such as lip biopsy, sialometry, or ocular evaluation, are limited.

\section{Anti-cofilin-1, Anti- $\alpha$-aenolase and Anti-RG12 Antibodies}

Cui et al. [40] identified three novel autoantibodies (anticofilin-1, anti- $\alpha$-enolase, and anti- RG12 antibodies) using proteomic techniques with the purpose of finding biomarkers for primary SjS and mucosa-associated lymphoid tissue (MALT) lymphoma. They observed that the level of the three autoantibodies were over-expressed in primary SjS/MALT lymphoma patients compared to primary SS patients and healthy controls. Receiver operating characteristic curve analysis revealed that the combination of the three autoantibodies were highly useful for the distinction of primary SjS and primary SjS/MALT lymphoma patients vs. controls and for the distinction of primary $\mathrm{SjS}$ patients vs. primary SjS/MALT lymphoma [40]. Anti-cofilin-1, anti- $\alpha$-aenolase, and anti-RGI2 antibodies are potential biomarkers of MALT lymphoma [34].

\section{MicroRNAs}

MicroRNAs (miRNAs) are a family of small, non-coding RNAs that regulate gene expression in a sequence-specific manner. Hundreds of miRNAs have been identified in almost all metazoan genomes, including worms, flies, plants and mammals. MiRNAs have diverse expression patterns and might regulate various developmental and physiological processes [41]. In recent years, an ever-increasing number of studies have reported that miRNAs are associated with SjS salivary gland tissue inflammation and are shown to be deregulated in salivary gland, cultured salivary gland-derived epithelial cells, and peripheral blood mononuclear cells from SjS patients. However, miRNAs may be released by all cells in the body, their specificity as diagnostic biomarkers can be impacted by high background [42]. Sembler-Møller et al. [43] showed that the miRNA expression profile in saliva, which is the direct product of the affected target organ, may enable to discriminate between primary SjS and non-primary SjS patients. In saliva of primary SjS, 14 miRNAs were significantly differentially expressed including downregulation of the miRNA-17 family. Further validation in larger cohorts is needed as well as functional analyses of the miRNAs in saliva [43].

\section{TREATMENTS OF SJÖGREN'S SYNDROME}

\section{Non-pharmacological Management for Systemic Disease}

Systemic dryness, fatigue, and pain are predominant symptoms in SjS patients, which affect the health-related quality of life [44]. In SjS patients, moderate to high-intensity exercise alleviate depression, fatigue scores, and physical function [45]. Lifestyle management includes sleep and activity management, rest, and cognitive behavioral therapy, which can be helpful to patients whose daily activity performance is significantly affected by fatigue of SjS patients [46].

\section{Current Treatments: Immunomodulation}

There is no curative treatment targeting the SjS-specific immune activation [47]. Symptomatic treatment is recommended to relieve common symptoms such as enervate fatigue, mucose dryness, and diffuse pain [48]. Unlike other autoimmune diseases, aggressive immunomodulation in 
patients with $\mathrm{SjS}$ is not recommended due to a lack of evidence base [46]. Although aggressive immunomodulation is not recommended in SjS patients, immunomodulation is required when serious complications affect internal organs. Extra-glandular manifestations are present in more than $70 \%$ of patients with $\mathrm{SjS}$ and about 15\% are severe [49]. The guidelines of the British and American Rheumatology Societies allow the use of immunomodulation agents considered the limited evidence and clinical experience $[46,50]$.

\section{1) Corticosteroids}

Although there have been no large trials about glucocorticoids for patients with SjS, corticosteroids are considered the first treatment option [46,51]. Prednisolone has been shown to improve systemic manifestations of SjS including cytopaenias, lung disease, myelopathy [52-55]. There is a study that low-dose prednisolone has shown improvements in sicca symptoms, but it is still controversial [56]. Short-term use of glucocorticoids reduce glandular enlargements, not sicca symptoms [48]. Despite Some benefits of corticosteroids in systemic manifestations of SjS, long-term use of corticosteroids should be carefully considered [46,48]. This is because long-term use of steroids increased the risk of infections, oral candidiasis, hyperglycemia, osteoporosis $[57,58]$.

\section{2) Hydroxychloroquine}

Hydroxychloroquine (HCQ) is an anti-malarial agent and possibly leads to immune inhibition [59]. Several studies reported the effect of HCQ in SjS patients [60]. Kruize et al. [61] investigated the effect of HCQ in SjS patients with high salivary IgG (mean $20.4 \mathrm{~g} / \mathrm{L}$ ), ESR (mean $32.5 \mathrm{~mm} /$ h). Although no significant effect on sicca symptoms, IgG, IgM, and ESR levels was reduced. Gottenberg et al. [62] performed a randomized controlled trial study on the clinical effects of HCQ in SjS patients with low disease activity (no systemic disease). HCQ decreased Ig levels and ESR in the treatment group at six months but did not reach significant levels in the end [62]. A meta-analysis of six previous studies failed to validate the effect of anti-malarial agent in SjS treatment and suggested that more quality research would be needed [63]. However, HCQ is effective in SLE. In a cohort study, the clinical flare-up was significantly increased after discontinued HCQ in SLE [63]. It is also effectively shown to improve subacute lupus, a symptom of SjS [64]. Therefore, more studies on the long-term use of HCQ in SjS patients are needed, but HCQ treatment was recommended with monitoring in patients with evidence of systemic disease $[46,48]$.

\section{3) Methotrexate}

Methotrexate (MTX) is an effective drug for rheumatoid arthritis $[65,66]$. MTX reduced RF and Ig levels in rheumatoid arthritis patients [67]. RF, which activates monocytes, present in a considerable proportion of SjS patients [68]. However, therapeutic evidence of MTX in SjS patients is insufficient. MTX has low to moderate clinical effects in SjS patients with myelopathy [51]. An open pilot study in 17 patients with SjS showed MTX improvement in sicca symptoms, arthralgia, glandular enlargement, dry cough. In contrast, objective results such as Shirmer's test, salivary flow rate, IgG levels, and ESR was not improved [69]. MTX may be useful in SjS patients with inflammatory arthritis, not sicca symptoms alone [46].

\section{4) Azathioprine}

Azathioprine (AZA) is a purine antagonist that disturb the function of endogenous purinase (essential for DNA replication and repair) [70]. AZA is effective immunomodulation in inflammatory bowel disease that was shown to induce apoptosis in activated lymphocytes [71]. AZA could be effective by inhibiting lymphocytes in SjS patients. There were numerous case reports about the effect of AZA in SjS patients with extra-glandular manifestations such as interstitial cystitis, interstitial lung disease, nephritis, myelopathy [71-75]. However, AZA is not routinely recommended in $\mathrm{SjS}$ patients without systemic manifestations $[46,50]$. In a double-blind placebo-controlled study on the effectiveness of AZA in SjS patients, there was no significant benefit and the frequency of side effects was high [76]. In conclusion, AZA has effectively been used to manage serious extraglandular manifestation, not for common symptoms in $\mathrm{SjS}$ patients.

\section{Future Treatments: Biologics}

Research on the pathogenesis of SjS increases interest in 
biologics targeting specific molecules. Although biologics are currently limited by the lack of licensing for the treatment of SjS, several studies have been reported testing the effectiveness of modified drugs that target specific immune cells [77-82]. The British Society for Rheumatology (BSR) recommends some biologics in certain clinical situations with severe extra-glandular manifestations. B-cell targeted therapy, the most frequently tested biological drug, may be considered for SjS patients with refractory systemic disease [44]. Where biologics are used, careful monitoring is required according to the recommendations of the latest BSR DMARD (disease-modifying anti-rheumatic drugs) guidelines [47].

\section{1) Rituximab}

Rituximab, a chimeric monoclonal antibody against the CD20 on B-Cells, could affect inflammatory disease-associated B cells [48]. An open-label trial on rituximab therapy in $\mathrm{SjS}$ patients had suggested that rituximab was not associated with any unexpected toxicities and had clinical benefits about subjective sicca symptoms [81]. Rituximab also reported its efficacy in the treatment of systemic SjS patients [78,80,83]. Recently, Delli et al. [84] reported that high $\mathrm{CD} 2 \mathrm{O}^{+} \mathrm{B}$ cells infiltration in the parotid parenchyma predicts a better response to rituximab treatment. Although more studies are needed, it suggests that rituximab has the potential to be used as a target agent for $\mathrm{SjS}$ treatment in the future.

\section{2) Belimumab}

Belimumab is a human monoclonal antibody which directly inhibits B cell-activating factor [85]. In an openlabel trial of belimumab, there was an improvement in SjS Disease Activity Index Score and non-malignant glandular enlargement [86]. A randomized clinical trial is underway for a combination of rituximab and belimumab in $\mathrm{SjS}$ patients. This combination could be beneficial for SjS treatment as depletion of B cells may have a more pronounced effect on pathogenic B cells [87].

\section{Management of Oral Manifestation}

1) Pharmacological management

Xerostomia is the majority character of SjS patients [88].
Long-term xerostomia can lead to various complications such as dental caries, oral candidiasis, burning pain, and traumatic ulcer [89]. Effective management of xerostomia is important because these discomforts are related to the quality of life in SjS patients [89,90]. Despite the importance of treatment, there is no golden method for oral manifestations treatment in SjS patients. Clinical evidence for the effectiveness of interventions for oral manifestations in $\mathrm{SjS}$ patients is lacking [90]. A meta-analysis studying immunomodulatory drugs was showed that no individual immunomodulatory drug had a clinical benefit in sicca symptoms [91]. Another meta-analysis study showed little evidence for immunomodulatory drugs for the management of xerostomia [92].

Pilocarpine hydrochloride is recommended for the treatment of xerostomia in SjS patients [46,90]. There are several randomized controlled trials showing that pilocarpine improved subjective dryness and increased salivary flow rate in SjS patients [93-95]. Results from a meta-analysis study confirmed that there is high-quality evidence for pilocarpine in the improvement of xerostomia [92]. Although pilocarpine is the most supportive treatment, dose-dependent side effects such as sweating, palpitations, and flushing may limit clinical use [96]. Topical application of pilocarpine is considered in patients with contra-indications such as uncontrolled asthma, chronic obstructive pulmonary disease, and acute iritis. A recent study of the use of topical liquid pilocarpine has shown promising symptom improvement with fewer side effects [97].

\section{2) Conservative management}

Saliva substitution is considered to alleviate symptoms of oral dryness in SjS patients. Neutral pH saliva substitutes containing fluoride are commercially available in various forms, including oral sprays, gels, and rinses $[44,46]$. The Cochrane study, which evaluated the effectiveness of topical treatments for dry mouth from any cause, reported no strong evidence of effectiveness [98]. The use of salivary substitutes is recommended because, despite limited evidence, patients report increased oral comfort without significant side effects $[46,98,99]$.

Sugar-free gum or sweets is often used in xerostomia patients, but there is little literature evidence to support its 
efficacy [46]. Chewing sugar-free gum increases saliva flow, and the xylitol in sugar-free gum may have a role in caries prevention [100]. According to the Cochrane review of the efficacy for xylitol, the use of fluoride toothpaste containing 10\% xylitol may reduce dental caries by $13 \%$ compared to fluoride-only toothpaste, but other xylitol-containing products showed insufficient evidence [101]. Acidic products and sugar-containing products may be more effective in stimulating saliva production but should be avoided because of their cariogenic potential. Murugesh et al. [102] reported that yogurt was more effective at salivary-stimulating than lemon juice, suggesting that yogurt is a potential candidate for xerostomia treatment.

\section{CONCLUSION}

The study of biomarkers in SjS is alive and well. Many studies are being carried out to discern pathological attributions of disease through associated biomarkers in SjS. Various biomarkers are reported in association with $\mathrm{SjS}$.

Many immunosuppressants have been used for severe extra-glandular manifestations in SjS, although they do not alleviate common symptoms of $\mathrm{SjS}$. For the alleviation of dry mouth, the application of various topical agents and in case of need the use of salivation-stimulant may be helpful.

To date, biomarkers for SjS preceding disease do not provide an opportunity to identify and study subjects before disease onset and treatments at this stage are not developed. However, many biomarkers can open a window for making additions to the diagnostic approach and to treatments in individuals for a role in the clinic in the future.

\section{CONFLICT OF INTEREST}

No potential conflict of interest relevant to this article was reported.

\section{ORCID}

\author{
Won Jung \\ https://orcid.org/0000-0002-8728-8013 \\ Kyung Eun Lee \\ https://orcid.org/0000-0001-8923-1478
}

\section{REFERENCES}

1. Fox RI. Sjögren's syndrome. Lancet 2005;366:321-331.

2. Ramos-Casals M, Tzioufas AG, Font J. Primary Sjögren's syndrome: new clinical and therapeutic concepts. Ann Rheum Dis 2005;64:347-354.

3. Ramos-Casals M, Brito-Zerón P, Sisó-Almirall A, Bosch X. Primary Sjogren syndrome. BMJ 2012;344:e3821.

4. Vitali C, Bombardieri S, Jonsson R, et al. Classification criteria for Sjögren's syndrome: a revised version of the European criteria proposed by the American-European Consensus Group. Ann Rheum Dis 2002;61:554-558.

5. Shiboski SC, Shiboski CH, Criswell L, et al. American College of Rheumatology classification criteria for Sjögren's syndrome: a data-driven, expert consensus approach in the Sjögren's International Collaborative Clinical Alliance cohort. Arthritis Care Res (Hoboken) 2012;64:475-487.

6. Shiboski CH, Shiboski SC, Seror R, et al. 2016 American College of Rheumatology/European League Against Rheumatism classification criteria for primary Sjögren's syndrome: a consensus and data-driven methodology involving three international patient cohorts. Arthritis Rheumatol 2017;69:35-45.

7. Chen W, Cao H, Lin J, Olsen N, Zheng SG. Biomarkers for primary Sjögren's syndrome. Genomics Proteomics Bioinformatics 2015;13:219-223.

8. Baldini C, Ferro F, Elefante E, Bombardieri S. Biomarkers for Sjögren’s syndrome. Biomark Med 2018;12:275-286.

9. Ko MY, Heo JY, Ok SM, Kim KH, Jeong SH, Ahn YW. The analysis and study of first visit outpatients in oral medicine. J Oral Med Pain 2013;38:137-142.

10. Lee KE. Sjögren's syndrome: an update on diagnostic, clinical, and basic aspects for oral medicine specialists. J Oral Med Pain 2018;43:99-111.

11. Clark G, Reichlin M, Tomasi TB Jr. Characterization of a soluble cytoplasmic antigen reactive with sera from patients with systemic lupus erythmatosus. J Immunol 1969;102:117-122.

12. Mattioli M, Reichlin M. Heterogeneity of RNA protein antigens reactive with sera of patients with systemic lupus erythematosus. Description of a cytoplasmic nonribosomal antigen. Arthritis Rheum 1974;17:421-429.

13. Alspaugh MA, Tan EM. Antibodies to cellular antigens in Sjögren's syndrome. J Clin Invest 1975;55:1067-1073.

14. Alspaugh M, Maddison P. Resolution of the identity of certain antigen-antibody systems in systemic lupus erythematosus and Sjögren's syndrome: an interlaboratory collaboration. Arthritis Rheum 1979;22:796-798.

15. Shen L, Suresh L. Autoantibodies, detection methods and panels for diagnosis of Sjögren's syndrome. Clin Immunol 2017;182:2429.

16. Bournia VK, Vlachoyiannopoulos PG. Subgroups of Sjögren syndrome patients according to serological profiles. J Autoimmun 2012;39:15-26.

17. Ingegnoli F, Castelli R, Gualtierotti R. Rheumatoid factors: clinical applications. Dis Markers 2013;35:727-734.

18. Fayyaz A, Kurien BT, Scofield RH. Autoantibodies in Sjögren's 
syndrome. Rheum Dis Clin North Am 2016;42:419-434.

19. Muro Y. Antinuclear antibodies. Autoimmunity 2005;38:3-9.

20. Nosal RS, Superville SS, Varacallo M. StatPearls. Biochemistry, antinuclear antibodies. Treasure Island: StatPearls; 2021.

21. Whitcher JP, Shiboski CH, Shiboski SC, et al. A simplified quantitative method for assessing keratoconjunctivitis sicca from the Sjögren's Syndrome International Registry. Am J Ophthalmol 2010;149:405-415.

22. Huo AP, Lin KC, Chou CT. Predictive and prognostic value of antinuclear antibodies and rheumatoid factor in primary Sjogren's syndrome. Int J Rheum Dis 2010;13:39-47.

23. Theander E, Jonsson R, Sjöström B, Brokstad K, Olsson P, Henriksson G. Prediction of Sjögren's syndrome years before diagnosis and identification of patients with early onset and severe disease course by autoantibody profiling. Arthritis Rheumatol 2015;67:2427-2436.

24. Haneji N, Nakamura T, Takio K, et al. Identification of alpha-fodrin as a candidate autoantigen in primary Sjögren's syndrome. Science 1997;276:604-607.

25. Hu Q, Wang D, Chen $\mathrm{W}$. The accuracy of the anti- $\alpha$-fodrin antibody test for diagnosis of Sjögren's syndrome: a meta-analysis. Clin Biochem 2013;46:1372-1376.

26. Willeke P, Gaubitz M, Schotte H, et al. Clinical and immunological characteristics of patients with Sjögren's syndrome in relation to alpha-fodrin antibodies. Rheumatology (Oxford) 2007;46:479483.

27. Qin Q, Wang H, Wang HZ, et al. Diagnostic accuracy of antialpha-fodrin antibodies for primary Sjögren's syndrome. Mod Rheumatol 2014;24:793-797.

28. Lee KE, Kang JH, Lee JW, et al. Anti-centromere antibodypositive Sjögren's syndrome: a distinct clinical subgroup? Int J Rheum Dis 2015;18:776-782.

29. Li Y, Bookman AAM. Comparison of effect on sicca symptoms of anticentromere antibody-positive Sjögren syndrome and primary Sjögren syndrome alone. J Rheumatol 2020;47:876-880.

30. Park Y, Lee J, Koh JH, et al. Clinical influences of anticentromere antibody on primary Sjögren's syndrome in a prospective Korean cohort. Korean J Intern Med 2021;36:1492-1503.

31. Shen L, Suresh L, Li H, et al. IL-14 alpha, the nexus for primary Sjögren's disease in mice and humans. Clin Immunol 2009;130:304-312.

32. Vishwanath S, Shen L, Suresh L, Ambrus JL Jr. Anti-salivary gland protein 1 antibodies in two patients with Sjogren's syndrome: two case reports. J Med Case Rep 2014;8:145.

33. Shen L, Kapsogeorgou EK, Yu M, et al. Evaluation of salivary gland protein 1 antibodies in patients with primary and secondary Sjogren's syndrome. Clin Immunol 2014;155:42-46.

34. Martín-Nares E, Hernández-Molina G. Novel autoantibodies in Sjögren's syndrome: a comprehensive review. Autoimmun Rev 2019;18:192-198.

35. Khovidhunkit W, Hachem JP, Medzihradszky KF, et al. Parotid secretory protein is an HDL-associated protein with anticandidal activity. Am J Physiol Regul Integr Comp Physiol 2005; 288:R1306-R1315.

36. Cecchettini A, Finamore F, Puxeddu I, Ferro F, Baldini C. Sali- vary extracellular vesicles versus whole saliva: new perspectives for the identification of proteomic biomarkers in Sjögren's syndrome. Clin Exp Rheumatol 2019;37 Suppl 118:240-248.

37. Deng C, Hu C, Chen S, et al. Meta-analysis of anti-muscarinic receptor type 3 antibodies for the diagnosis of Sjögren syndrome. PLoS One 2015;10:e0116744.

38. Zuo J, Williams AE, Park YJ, et al. Muscarinic type 3 receptor autoantibodies are associated with anti-SSA/Ro autoantibodies in Sjögren's syndrome. J Immunol Methods 2016;437:28-36.

39. Mona M, Mondello S, Hyon JY, et al. Clinical usefulness of antimuscarinic type 3 receptor autoantibodies in patients with primary Sjögren's syndrome. Clin Exp Rheumatol 2021;39:795-803.

40. Cui L, Elzakra N, Xu S, Xiao GG, Yang Y, Hu S. Investigation of three potential autoantibodies in Sjogren's syndrome and associated MALT lymphoma. Oncotarget 2017;8:30039-30049.

41. He L, Hannon GJ. MicroRNAs: small RNAs with a big role in gene regulation. Nat Rev Genet 2004;5:522-531.

42. Reale M, D'Angelo C, Costantini E, Laus M, Moretti A, Croce A. MicroRNA in Sjögren's syndrome: their potential roles in pathogenesis and diagnosis. J Immunol Res 2018;2018:7510174.

43. Sembler-Møller ML, Belstrøm D, Locht H, Pedersen AML. Distinct microRNA expression profiles in saliva and salivary gland tissue differentiate patients with primary Sjögren's syndrome from non-Sjögren's sicca patients. J Oral Pathol Med 2020;49:10441052.

44. Ramos-Casals M, Brito-Zerón P, Bombardieri S, et al. EULAR recommendations for the management of Sjögren's syndrome with topical and systemic therapies. Ann Rheum Dis 2020;79:318.

45. Strömbeck B, Jacobsson LT. The role of exercise in the rehabilitation of patients with systemic lupus erythematosus and patients with primary Sjögren's syndrome. Curr Opin Rheumatol 2007;19:197-203.

46. Price EJ, Rauz S, Tappuni AR, et al. The British Society for Rheumatology guideline for the management of adults with primary Sjögren's syndrome. Rheumatology (Oxford) 2017;56:e24-e48.

47. van der Heijden EHM, Kruize AA, Radstake TRDJ, van Roon JAG. Optimizing conventional DMARD therapy for Sjögren's syndrome. Autoimmun Rev 2018;17:480-492.

48. Fox RI, Fox CM, Gottenberg JE, Dörner T. Treatment of Sjögren's syndrome: current therapy and future directions. Rheumatology (Oxford) 2021;60:2066-2074.

49. Baldini C, Pepe P, Quartuccio L, et al. Primary Sjogren's syndrome as a multi-organ disease: impact of the serological profile on the clinical presentation of the disease in a large cohort of Italian patients. Rheumatology (Oxford) 2014;53:839-844.

50. Carsons SE, Vivino FB, Parke A, et al. Treatment guidelines for rheumatologic manifestations of Sjögren's syndrome: use of biologic agents, management of fatigue, and inflammatory musculoskeletal pain. Arthritis Care Res (Hoboken) 2017;69:517-527.

51. Rogers SJ, Williams CS, Román GC. Myelopathy in Sjögren's syndrome: role of nonsteroidal immunosuppressants. Drugs 2004;64:123-132.

52. Reina D, Roig Vilaseca D, Torrente-Segarra V, et al. Sjögren's syndrome-associated interstitial lung disease: a multicenter 
study. Reumatol Clin 2016;12:201-205.

53. Enomoto Y, Takemura T, Hagiwara E, et al. Prognostic factors in interstitial lung disease associated with primary Sjögren's syndrome: a retrospective analysis of 33 pathologically-proven cases. PLoS One 2013;8:e73774.

54. Hattori N, Nakashima H, Usui T, et al. [Successful treatment with prednisolone for autoimmune myelofibrosis accompanied with Sjögren syndrome]. Rinsho Ketsueki 2007;48:1539-1543. Japanese.

55. Williams CS, Butler E, Román GC. Treatment of myelopathy in Sjögren syndrome with a combination of prednisone and cyclophosphamide. Arch Neurol 2001;58:815-819.

56. Miyawaki S, Nishiyama S, Matoba K. Efficacy of low-dose prednisolone maintenance for saliva production and serological $\mathrm{ab}$ normalities in patients with primary Sjögren's syndrome. Intern Med 1999;38:938-943.

57. Ramos-Casals M, Brito-Zerón P, Sisó-Almirall A, Bosch X, Tzioufas AG. Topical and systemic medications for the treatment of primary Sjögren's syndrome. Nat Rev Rheumatol 2012;8:399411.

58. López-Pintor RM, Fernández Castro M, Hernández G. Oral involvement in patients with primary Sjögren's syndrome. Multidisciplinary care by dentists and rheumatologists. Reumatol Clin 2015;11:387-394.

59. Ben-Zvi I, Kivity S, Langevitz P, Shoenfeld Y. Hydroxychloroquine: from malaria to autoimmunity. Clin Rev Allergy Immunol 2012;42:145-153.

60. Tishler M, Yaron I, Shirazi I, Yaron M. Hydroxychloroquine treatment for primary Sjögren's syndrome: its effect on salivary and serum inflammatory markers. Ann Rheum Dis 1999;58:253256.

61. Kruize AA, Hené RJ, Kallenberg CG, et al. Hydroxychloroquine treatment for primary Sjögren's syndrome: a two year double blind crossover trial. Ann Rheum Dis 1993;52:360-364.

62. Gottenberg JE, Ravaud P, Puéchal X, et al. Effects of hydroxychloroquine on symptomatic improvement in primary Sjögren syndrome: the JOQUER randomized clinical trial. JAMA 2014;312:249-258.

63. Coy V. Granados C, Gil D, et al. Antimalarials for Sjogren's syndrome treatment in adults, meta-analysis. Paper presented at: 2012 ACR/ARHP Annual Meeting; 2012 Nov 9-14; Washington, D.C., USA. pp. 64.

64. Brito-Zerón P, Sisó-Almirall A, Kostov B, Bosch X, Tzioufas AG, Ramos-Casals M. B-cell targeted therapies in primary Sjögren syndrome. In: Bosch X, Ramos-Casals M, Khamashta MA, eds. Drugs targeting B-cells in autoimmune diseases. Basel: Springer; 2014. pp. 111-138.

65. Kennedy T, McCabe C, Struthers G, et al. BSR guidelines on standards of care for persons with rheumatoid arthritis. Rheumatology (Oxford) 2005;44:553-556.

66. Wessels JA, Huizinga TW, Guchelaar HJ. Recent insights in the pharmacological actions of methotrexate in the treatment of rheumatoid arthritis. Rheumatology (Oxford) 2008;47:249-55.

67. Alarcón GS, Schrohenloher RE, Bartolucci AA, Ward JR, Williams HJ, Koopman WJ. Suppression of rheumatoid factor pro- duction by methotrexate in patients with rheumatoid arthritis. Evidence for differential influences of therapy and clinical status on IgM and IgA rheumatoid factor expression. Arthritis Rheum 1990;33:1156-1161.

68. Wijngaarden S, van Roon JA, van de Winkel JG, Bijlsma JW, Lafeber FP. Down-regulation of activating Fcgamma receptors on monocytes of patients with rheumatoid arthritis upon methotrexate treatment. Rheumatology (Oxford) 2005;44:729-734.

69. Skopouli FN, Jagiello P, Tsifetaki N, Moutsopoulos HM. Methotrexate in primary Sjögren's syndrome. Clin Exp Rheumatol 1996;14:555-558.

70. Bardek I, Milavec-Puretić V, Lipozencić J. Azathioprine in dermatology. Acta Dermatovenerol Croat 2007;15:264-268.

71. Stocco G, Pelin M, Franca R, et al. Pharmacogenetics of azathioprine in inflammatory bowel disease: a role for glutathione-Stransferase? World J Gastroenterol 2014;20:3534-3541.

72. Darrieutort-Laffite C, André V, Hayem G, et al. Sjögren's syndrome complicated by interstitial cystitis: a case series and literature review. Joint Bone Spine 2015;82:245-250.

73. Deheinzelin D, Capelozzi VL, Kairalla RA, Barbas Filho JV, Saldiva PH, de Carvalho CR. Interstitial lung disease in primary Sjögren's syndrome. Clinical-pathological evaluation and response to treatment. Am J Respir Crit Care Med 1996;154(3 Pt 1):794-799.

74. Kaufman I, Schwartz D, Caspi D, Paran D. Sjögren's syndromenot just Sicca: renal involvement in Sjögren's syndrome. Scand J Rheumatol 2008;37:213-218.

75. Hawley RJ, Hendricks WT. Treatment of Sjögren syndrome myelopathy with azathioprine and steroids. Arch Neurol 2002;59:875; author reply 876.

76. Price EJ, Rigby SP, Clancy U, Venables PJ. A double blind placebo controlled trial of azathioprine in the treatment of primary Sjögren's syndrome. J Rheumatol 1998;25:896-899.

77. Meiners PM, Vissink A, Kroese FG, et al. Abatacept treatment reduces disease activity in early primary Sjögren's syndrome (open-label proof of concept ASAP study). Ann Rheum Dis 2014;73:1393-1396.

78. Carubbi F, Cipriani P, Marrelli A, et al. Efficacy and safety of rituximab treatment in early primary Sjögren's syndrome: a prospective, multi-center, follow-up study. Arthritis Res Ther 2013;15:R172.

79. Adler S, Körner M, Förger F, Huscher D, Caversaccio MD, Villiger PM. Evaluation of histologic, serologic, and clinical changes in response to abatacept treatment of primary Sjögren's syndrome: a pilot study. Arthritis Care Res (Hoboken) 2013;65:1862-1868.

80. Gottenberg JE, Cinquetti G, Larroche C, et al. Efficacy of rituximab in systemic manifestations of primary Sjogren's syndrome: results in 78 patients of the AutoImmune and Rituximab registry. Ann Rheum Dis 2013;72:1026-1031.

81. St Clair EW, Levesque MC, Prak ET, et al. Rituximab therapy for primary Sjögren's syndrome: an open-label clinical trial and mechanistic analysis. Arthritis Rheum 2013;65:1097-1106.

82. Steinfeld SD, Tant L, Burmester GR, et al. Epratuzumab (humanised anti-CD22 antibody) in primary Sjögren's syndrome: an open-label phase I/II study. Arthritis Res Ther 2006;8:R129. 
83. Pijpe J, van Imhoff GW, Spijkervet FK, et al. Rituximab treatment in patients with primary Sjögren's syndrome: an openlabel phase II study. Arthritis Rheum 2005;52:2740-2750.

84. Delli K, Haacke EA, Kroese FG, et al. Towards personalised treatment in primary Sjögren's syndrome: baseline parotid histopathology predicts responsiveness to rituximab treatment. Ann Rheum Dis 2016;75:1933-1938.

85. Srivastava A. Belimumab in systemic lupus erythematosus. Indian J Dermatol 2016;61:550-553.

86. Mariette X, Seror R, Quartuccio L, et al. Efficacy and safety of belimumab in primary Sjögren's syndrome: results of the BELISS open-label phase II study. Ann Rheum Dis 2015;74:526-531.

87. De Vita S, Quartuccio L, Salvin S, et al. Sequential therapy with belimumab followed by rituximab in Sjögren's syndrome associated with B-cell lymphoproliferation and overexpression of BAFF: evidence for long-term efficacy. Clin Exp Rheumatol 2014;32:490-494.

88. Wang B, Chen S, Zheng Q, et al. Early diagnosis and treatment for Sjögren's syndrome: current challenges, redefined disease stages and future prospects. J Autoimmun 2021;117:102590.

89. Cartee DL, Maker S, Dalonges D, Manski MC. Sjögren's syndrome: oral manifestations and treatment, a dental perspective. J Dent Hyg 2015;89:365-371.

90. Sutcliffe N, Recchioni A, Hilmi S, Rauz S, Tappuni AR. What's new in ocular and oral aspects of Sjögren's syndrome and do new treatments work? Rheumatology (Oxford) 2021;60:10341041.

91. Chu LL, Cui K, Pope JE. Meta-analysis of treatment for primary Sjögren's syndrome. Arthritis Care Res (Hoboken) 2020;72:10111021.

92. Al Hamad A, Lodi G, Porter S, Fedele S, Mercadante V. Interventions for dry mouth and hyposalivation in Sjögren's syndrome: a systematic review and meta-analysis. Oral Dis 2019;25:10271047.

93. Cifuentes M, Del Barrio-Díaz P, Vera-Kellet C. Pilocarpine and artificial saliva for the treatment of xerostomia and xerophthal- mia in Sjögren syndrome: a double-blind randomized controlled trial. Br J Dermatol 2018;179:1056-1061.

94. Rhodus NL, Schuh MJ. Effects of pilocarpine on salivary flow in patients with Sjögren's syndrome. Oral Surg Oral Med Oral Pathol 1991;72:545-549.

95. Vivino FB, Al-Hashimi I, Khan Z, et al. Pilocarpine tablets for the treatment of dry mouth and dry eye symptoms in patients with Sjögren syndrome: a randomized, placebo-controlled, fixeddose, multicenter trial. P92-01 Study Group. Arch Intern Med 1999;159:174-181.

96. Gil-Montoya JA, Silvestre FJ, Barrios R, Silvestre-Rangil J. Treatment of xerostomia and hyposalivation in the elderly: a systematic review. Med Oral Patol Oral Cir Bucal 2016;21:e355-e366.

97. Watanabe M, Yamada C, Komagata Y, Kikuchi H, Hosono H, Itagaki F. New low-dose liquid pilocarpine formulation for treating dry mouth in Sjögren's syndrome: clinical efficacy, symptom relief, and improvement in quality of life. J Pharm Health Care Sci 2018;4:4.

98. Furness S, Worthington HV, Bryan G, Birchenough S, McMillan R. Interventions for the management of dry mouth: topical therapies. Cochrane Database Syst Rev 2011;(12):CD008934.

99. Mouly S, Salom M, Tillet Y, et al. Management of xerostomia in older patients: a randomised controlled trial evaluating the efficacy of a new oral lubricant solution. Drugs Aging 2007;24:957965.

100. Milgrom P, Ly KA, Tut OK, et al. Xylitol pediatric topical oral syrup to prevent dental caries: a double-blind randomized clinical trial of efficacy. Arch Pediatr Adolesc Med 2009;163:601-607.

101. Riley P, Moore D, Ahmed F, Sharif MO, Worthington HV. Xylitolcontaining products for preventing dental caries in children and adults. Cochrane Database Syst Rev 2015;(3):CD010743.

102. Murugesh J, Annigeri RG, Raheel SA, Azzeghaiby S, Alshehri M, Kujan 0. Effect of yogurt and pH equivalent lemon juice on salivary flow rate in healthy volunteers - an experimental crossover study. Interv Med Appl Sci 2015;7:147-151. 